\title{
Counterion effects in iminium-activated electrophilic aromatic substitutions of pyrroles $\dagger$
}

\author{
Sami Lakhdar and Herbert Mayr* \\ Received 8th October 2010, Accepted 9th November 2010 \\ DOI: $10.1039 / \mathbf{c 0 c c 0 4 2 9 5 a}$
}

Electrophilic substitution of pyrroles by $\alpha, \beta$-unsaturated iminium ions is slow in acetonitrile when only weakly basic counterions are present. When the reactions are carried out in the presence of $\mathrm{KCF}_{3} \mathrm{CO}_{2}$, fast deprotonation of the intermediate $\sigma$-adducts occurs, and the rate constant for the rate-determining $\mathrm{CC}$ bond-forming step can be predicted from the electrophilicity parameter $E$ of the iminium ion and the $N$ and $s$ parameters of the pyrroles.

Iminium activation has become one of the most important methods for the enantioselective formation of CC bonds. ${ }^{1}$ Recently, much attention has been paid to the mechanism of these reactions including the isolation and characterisation of the intermediates. ${ }^{2}$

In previous work, we have studied the kinetics of a series of $\alpha, \beta$-unsaturated iminium ions with ketene acetals in order to determine their electrophilicity parameters $E$ according to eqn $(1)^{3}$ where electrophiles are characterised by one parameter $(E)$, while two parameters $(N$ and $s$ ) are used for the characterisation of nucleophiles. ${ }^{4}$

$$
\log k\left(20^{\circ} \mathrm{C}\right)=s(N+E)
$$

We now report on the applicability of eqn (1) for predicting the scope and limitations of iminium-activated electrophilic aromatic substitutions. ${ }^{5}$ As the rate constants accessible by eqn (1) refer to the electrophile-nucleophile combination step, knowledge of the rate-determining step of this reaction cascade was needed. Paras and MacMillan reported that imidazolidinone-catalysed reactions of $\alpha, \beta$-unsaturated aldehydes with pyrroles proceed well with $\mathrm{CF}_{3} \mathrm{CO}_{2} \mathrm{H}$ as a cocatalyst, but give low yields and enantioselectivities, when strong acids such as $\mathrm{CF}_{3} \mathrm{SO}_{3} \mathrm{H}$, TsOH or $\mathrm{HCl}$ are employed. ${ }^{6}$ As this observation may be due to reversible formation of the $\sigma$-adduct from the iminium ion $\mathbf{1}$ and the pyrroles, ${ }^{6}$ we have systematically studied the effect of the counterions on the rates of these reactions.

The kinetics of the reactions of the iminium ion $\mathbf{1}$ with the ketene acetal 2a and the pyrrole $\mathbf{2 b}$ (Scheme 1) were determined photometrically by following the disappearance of the absorbance of $\mathbf{1}$ at $360 \mathrm{~nm}$ according to the procedure described previously. ${ }^{3,7}$

All kinetic experiments were performed under first-order conditions using 25 to 800 equivalents of 2 . The reactions of

Department Chemie, Ludwig-Maximilians-Universität München, Butenandtstr. 5-13 (Haus F), 81377 München, Germany.

E-mail: Herbert.Mayr@cup.uni-muenchen.de;

Fax: +4989218077717

$\dagger$ Electronic supplementary information (ESI) available: Details of the kinetic experiments, synthetic procedures and product characterisation. See DOI: $10.1039 / \mathrm{c} 0 \mathrm{cc} 04295 \mathrm{a}$

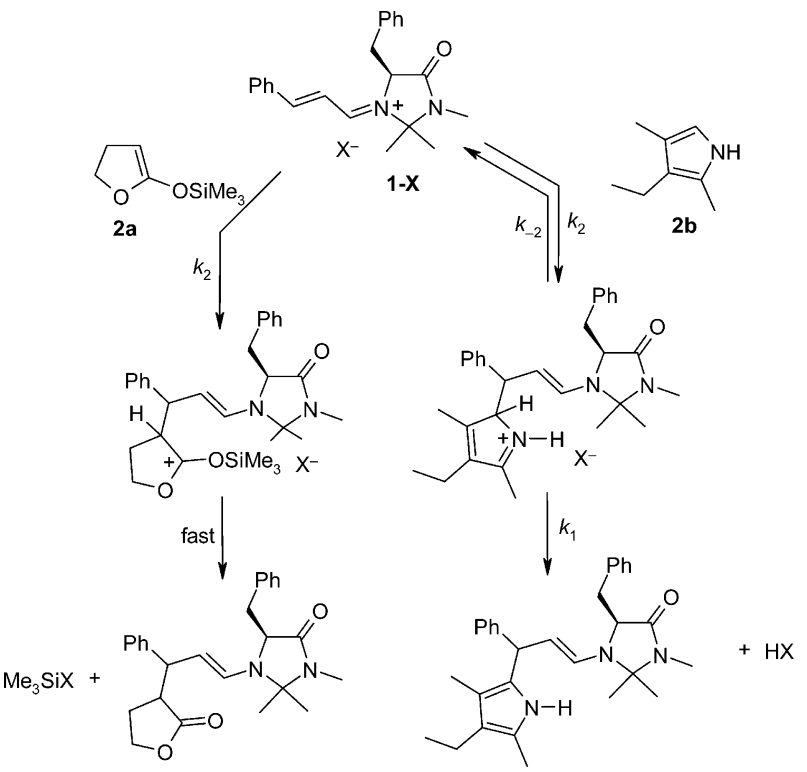

Scheme 1 Mechanism of the reactions of different iminium salts 1-X with $\pi$-nucleophiles.

Table 1 Counterion effect on the second-order rate constants $k_{2}\left(\mathrm{M}^{-1} \mathrm{~s}^{-1}\right)$ for the reactions of the iminium salts $1-\mathrm{X}$ with the ketene acetal 2a in $\mathrm{CH}_{2} \mathrm{Cl}_{2}$ and the apparent second-order rate constants $k_{2}^{\prime}\left(\mathrm{M}^{-1} \mathrm{~s}^{-1}\right)$ for the reactions of $1-\mathrm{X}$ with kryptopyrrole 2b in $\mathrm{CH}_{3} \mathrm{CN}$ at $20{ }^{\circ} \mathrm{C}$

\begin{tabular}{lll}
\hline $\mathbf{1}-\mathrm{X}$ & $k_{2}(\mathbf{2 a})$ & $k_{2}^{\prime}(\mathbf{2 b})$ \\
\hline $\mathbf{1}-\mathrm{PF}_{6}$ & $1.14 \times 10^{4}$ & $6.27 \times 10^{1}$ \\
$\mathbf{1}-\mathrm{BF}_{4}$ & $1.19 \times 10^{4}$ & $5.60 \times 10^{1}$ \\
$\mathbf{1}-\mathrm{OTf}$ & $9.06 \times 10^{3 a}$ & $2.32 \times 10^{1}$ \\
$\mathbf{1}-\mathrm{Br}$ & $4.53 \times 10^{3}$ & $6.43 \times 10^{1}$ \\
$\mathbf{1}-\mathrm{CF}_{3} \mathrm{CO}_{2}{ }^{b}$ & $6.76 \times 10^{3}$ & $5.94 \times 10^{2}$
\end{tabular}

${ }^{a}$ From ref. 3. ${ }^{b} \mathbf{1}-\mathrm{CF}_{3} \mathrm{CO}_{2}$ was generated by addition of an equimolar amount of cinnamaldehyde to imidazolidinium trifluoroacetate in acetonitrile.

1-X with the ketene acetal 2a showed monoexponential decays over more than 4 half-lives. Deviations from the first-order rate law were observed for the reactions of $\mathbf{1}-\mathrm{X}$ with $\mathbf{2 b}$ at conversions above $70 \%$. The second-order rate constants $k_{2}$ and $k_{2}^{\prime}$ listed in Table 1 are the slopes of the linear plots of the observed first-order rate constants $k_{\text {obs }} v s$. [2].

Table 1 shows the different counterion effects on the reactions with the nucleophiles $\mathbf{2} \mathbf{a}$ and $\mathbf{2 b}$. While the second-order rate constants of the reactions of $\mathbf{1}-\mathrm{X}$ with $\mathbf{2 a}$ vary by less than a factor of 3 , the rates of the reactions of $\mathbf{1}-\mathrm{X}$ with $\mathbf{2} \mathbf{b}$ are significantly affected by the counterions; in the concentration range investigated, the iminium trifluoroacetate $1-\mathrm{CF}_{3} \mathrm{CO}_{2}$ reacts 26 times faster with $\mathbf{2 b}$ than the iminium triflate $\mathbf{1}-\mathrm{OTf}$. 
This behaviour may be rationalised by the reversible attack of $\mathbf{1}$ at the pyrrole $\mathbf{2} \mathbf{b}$ and subsequent deprotonation of the intermediate $\sigma$-adduct. ${ }^{8}$ Due to its higher basicity, ${ }^{9} \mathrm{CF}_{3} \mathrm{CO}_{2}{ }^{-}$ can be assumed to abstract the proton faster than the other anions investigated, all of which are conjugate bases of very strong acids.

In line with this hypothesis, first-order kinetics over more than four half-lives have been observed when the reaction of the iminium salt $\mathbf{1}-\mathrm{BF}_{4}$ with $\mathbf{2} \mathbf{b}$ was studied in the presence of high concentrations of potassium trifluoroacetate. With the assumption that $\mathrm{CF}_{3} \mathrm{CO}_{2}{ }^{-}$serves as the base to deprotonate the intermediate $\sigma$-adduct, the rate law for the reaction of $\mathbf{1}-\mathrm{BF}_{4}$ with $\mathbf{2 b}$ is given by eqn (2), where the last term corresponds to the ratio of deprotonation of the intermediate $k_{1}\left[\mathrm{CF}_{3} \mathrm{CO}_{2}^{-}\right]$divided by the sum of the forward plus backward reaction (the meaning of the rate constants is specified in Scheme 1). For [2b] $\gg[\mathbf{1}]$, the concentration of $[\mathbf{2 b}]$ can be considered to be constant, and one obtains eqn (3).

$$
\begin{aligned}
-\frac{\mathrm{d}[\mathbf{1}]}{\mathrm{d} t} & =k_{2}[\mathbf{1}][\mathbf{2} \mathbf{b}] \frac{k_{1}\left[\mathbf{C F}_{\mathbf{3}} \mathbf{C O}_{\mathbf{2}}^{-}\right]}{k_{1}\left[\mathbf{C F}_{\mathbf{3}} \mathbf{C} \mathbf{O}_{\mathbf{2}}^{-}\right]+k_{-2}} \\
\frac{1}{k_{\mathrm{obs}}} & =\frac{1}{k_{2}[\mathbf{2} \mathbf{b}]}+\frac{k_{-2}}{k_{1} k_{2}[\mathbf{2} \mathbf{b}]} \frac{1}{\left[\mathbf{C F}_{\mathbf{3}} \mathbf{C O}_{\mathbf{2}}^{-}\right]}
\end{aligned}
$$

According to eqn (3), the intercept of the plot of $1 / k_{\text {obs }} v s$. $1 /\left[\mathrm{CF}_{3} \mathrm{CO}_{2}^{-}\right]$yields the rate constant for the first step of the reaction cascade (Fig. 1). Comparison of this value $\left(k_{2}=1.3 \times 10^{4} \mathrm{M}^{-1} \mathrm{~s}^{-1}\right)$ with the entries 1 to 4 in the right column of Table 1 shows that the rate constants $k_{2}^{\prime}$ observed in the absence of $\mathrm{CF}_{3} \mathrm{CO}_{2}{ }^{-}$are 202 to 560 times smaller than $k_{2}$, indicating that triflate, tetrafluoroborate, hexafluorophosphate, and bromide ions are poor bases for the removal of protons from the pyrrolium species. It should be noted that also the last entry in the right column of Table 1 is 22 times smaller than the second-order rate constant derived from Fig. 1, indicating that at low ion concentrations, also the first step of the reaction of $\mathbf{1}-\mathrm{CF}_{3} \mathrm{CO}_{2}$ with $\mathbf{2 b}$ is reversible.

The method described in Fig. 1 for determining the secondorder rate constant $k_{2}$ for the attack of $\mathbf{1}$ at the pyrrole $\mathbf{2 b}$ has analogously been employed for determining the rate constant of attack of $\mathbf{1}$ at the pyrroles $\mathbf{2} \mathbf{c}-\mathbf{g}$. Table 2 shows that the experimental rate constants $k_{2}$ agree within a factor of 8 with

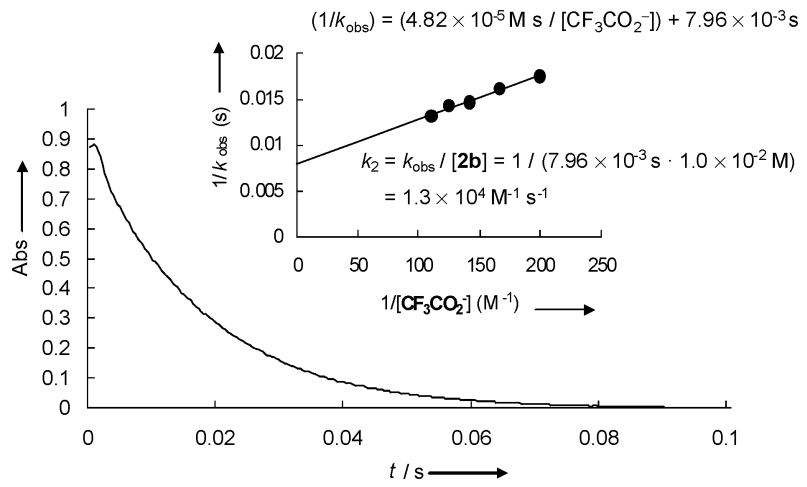

Fig. 1 Exponential decay of the absorbance at $360 \mathrm{~nm}$ during the reaction of $1-\mathrm{BF}_{4}\left(5.0 \times 10^{-5} \mathrm{M}\right)$ with $2 \mathbf{b}\left(1.0 \times 10^{-2} \mathrm{M}\right)$ and $\mathrm{CF}_{3} \mathrm{CO}_{2}^{-}\left(5.0 \times 10^{-3} \mathrm{M}\right)$. Inset: determination of the second-order rate constant $k_{2}$.
Table 2 Comparison of calculated and experimental secondorder rate constants $\left(\mathrm{M}^{-1} \mathrm{~s}^{-1}\right)$ of the reactions of pyrroles $\mathbf{2} \mathbf{b}-\mathbf{g}$ with the iminium ion $\mathbf{1}\left(20{ }^{\circ} \mathrm{C}, \mathrm{CH}_{3} \mathrm{CN}\right)$ in the presence of

\begin{tabular}{|c|c|c|c|c|}
\hline Pyrroles 2 & $N, s^{a}$ & $k_{2}^{\text {calcd } b}$ & $k_{2}^{\exp c}$ & $k_{2}^{\text {calcd }}$ \\
\hline $2 b$ & $11.63,0.95$ & $2.3 \times 10^{4}$ & $1.3 \times 10^{4}$ & 1.8 \\
\hline $2 c$ & $10.67,0.91$ & $2.1 \times 10^{3}$ & $3.5 \times 10^{3}$ & 0.60 \\
\hline $2 d$ & $8.69,1.01$ & $3.9 \times 10^{1}$ & 5.3 & 7.4 \\
\hline $2 e$ & $8.01,0.96$ & 5.9 & 3.6 & 1.6 \\
\hline $2 \mathrm{f}$ & $5.85,1.03$ & $4.1 \times 10^{-2}$ & $7.2 \times 10^{-3}$ & 5.7 \\
\hline $2 \mathrm{~g}$ & $4.63,1.00$ & $2.7 \times 10^{-3}$ & $6.8 \times 10^{-4}$ & 4.0 \\
\hline
\end{tabular}
added trifluoroacetate

${ }^{a}$ From ref. 10. ${ }^{b}$ Calculated by eqn (1) by using the electrophilicity parameters $E=-7.2$ for $\mathbf{1}$ from ref. $3 .{ }^{c}$ Derived from the intercepts of the linear correlations of $1 / k_{\text {obs }}$ with $1 /\left[\mathrm{CF}_{3} \mathrm{CO}_{2}{ }^{-}\right]$. Details are given in the ESI. $\dagger$

those calculated from eqn (1), i.e., the $E, N$, and $s$ parameters can be employed for determining the scope and limitations of iminium-catalysed reactions.

As the $N$ and $s$ parameters of the pyrroles $\mathbf{2} \mathbf{b}-\mathbf{g}^{10}$ have been derived from their reactions with benzhydrylium ions (reference electrophiles) and the parameter $E$ for $\mathbf{1}$ has been derived from its reactivity toward ketene acetals, ${ }^{3}$ this agreement is further evidence for the power of the three parameter eqn (1) to provide reliable estimates for second-order rate constants in a reactivity range presently covering 40 orders of magnitude.

Accordingly, treatment of an acetonitrile : water $(1: 1)$ solution of the iminium salts $1-\mathrm{PF}_{6}$ with 5 equivalents of the pyrroles $\mathbf{2} \mathbf{b}-\mathbf{g}$ in the presence of 5 to 6 equivalents of potassium trifluoroacetate and subsequent reduction with $\mathrm{NaBH}_{4}$ allowed us to isolate the alcohols $\mathbf{3 b}-\mathbf{g}$ in 78 to $99 \%$ yield (Table 3). ${ }^{11}$ In contrast, the reaction of $\mathbf{2 b}$ with $\mathbf{1}-\mathrm{PF}_{6}$ gave only $15 \%$ of $\mathbf{3 b}$ when the reaction was carried out under the same conditions but without potassium trifluoroacetate. These observations show clearly that the presence of base is essential for the success of the reaction. ${ }^{12}$

The high reversibility of the attack of the iminium ions at pyrroles in the absence of $\mathrm{CF}_{3} \mathrm{CO}_{2}{ }^{-}$not only accounts for the lower conversion rates of $1-\mathrm{X}\left(\mathrm{X}=\mathrm{PF}_{6}, \mathrm{BF}_{4}, \mathrm{OTf}, \mathrm{Br}\right)$ but also for the erosion of enantioselectivity which was reported 
Table 3 Products of the reactions of $\mathbf{1}-\mathrm{PF}_{6}$ with pyrroles $\mathbf{2} \mathbf{b}-\mathbf{g}$ in the presence of potassium trifluoroacetate ${ }^{a}$

\begin{tabular}{|c|c|c|}
\hline Pyrrole & Product & Yield $^{b}(\%)$ \\
\hline $2 b$ & $3 \mathbf{b}$ & $94(15)^{c}$ \\
\hline $2 c$ & $3 c$ & 97 \\
\hline 2d & 3d & 83 \\
\hline $2 e$ & $3 \mathbf{e}$ & 99 \\
\hline $2 f$ & $3 f$ & $78^{d}$ \\
\hline $2 g$ & $3 g$ & 80 \\
\hline \multicolumn{3}{|c|}{$\begin{array}{l}{ }^{a} \text { Reaction conditions: iminium salt } \mathbf{1}-\mathrm{PF}_{6}(0.50 \mathrm{mmol}) \text {, pyrroles } \mathbf{2} \mathbf{b}-\mathbf{g} \\
(2.46 \mathrm{mmol}) \text {, potassium trifluoroacetate }(2.63 \mathrm{mmol}) \text { in acetonitrile- } \\
\text { water mixture } 1: 1 \text { at }-20{ }^{\circ} \mathrm{C}, 30 \mathrm{~min} \text {. Then, in situ reduction of the } \\
\text { aldehydes by } \mathrm{NaBH}_{4} \text { to the corresponding primary alcohols } \mathbf{3 b}-\mathbf{g} \text {. } \\
{ }^{b} \text { Yield of isolated product after column chromatography on silica } \\
\text { gel. }{ }^{c} \text { Without potassium trifluoroacetate. }{ }^{d} \text { ee }>99 \% \text { (for details see } \\
\text { p S31 of the ESI } \dagger) \text {. }\end{array}$} \\
\hline
\end{tabular}

by Paras and MacMillan for the imidazolidinium catalysed reaction of cinnamaldehyde with $\mathbf{2 f}$. ${ }^{6}$ Only when high concentrations of the more basic trifluoroacetate counterion are present, are the $\sigma$-adducts formed irreversibly. As a consequence, the high enantioselectivity of the addition step, which has been studied computationally by Houk et al., ${ }^{13}$ is fully transmitted into the final product. In line with this interpretation, the reaction of $\mathbf{2} \mathbf{f}$ with $\mathbf{1}-\mathrm{PF}_{6}$ gave $\mathbf{3 f}$ with $>99 \%$ ee, when the reaction was carried out in $\mathrm{CH}_{3} \mathrm{CN}-\mathrm{H}_{2} \mathrm{O}$ $(1: 1)$ in the presence of $\mathrm{KCF}_{3} \mathrm{CO}_{2}$ (Table 3). Presently, we are investigating the effect of the co-catalyst on the formation of the iminium ion, in order to achieve a quantitative description of the whole organocatalytic cycle.

We thank Dr Armin R. Ofial and Dr Tanja Kanzian for helpful discussions and the Deutsche Forschungsgemeinschaft (Ma 673/21-3) for generous support.

\section{Notes and references}

1 For reviews on asymmetric iminium catalysis, see: (a) J. Seayad and B. List, Org. Biomol. Chem., 2005, 3, 719; (b) B. List, Chem. Commun., 2006, 819; (c) G. Lelais and D. W. C. MacMillan, Aldrichimica Acta, 2006, 39, 79; (d) A. Erkkilä, I. Majander and P. M. Pihko, Chem. Rev., 2007, 107, 5416; (e) S. B. Tsogoeva, Eur. J. Org. Chem., 2007, 1701; (f) D. Almași, D. A. Alonso and C. Nájera, Tetrahedron: Asymmetry, 2007, 18, 299; $(g)$ B. Brazier and N. C. O. Tomkinsson, Top. Curr. Chem., 2010, 291, 281; (h) for a review on organocatalysed Friedel-Crafts reactions, see: V. Terrasson, R. M. De Figueiredo and J. M. Campagne, Eur. J. Org. Chem., 2010, 2635.

2 (a) D. Seebach, U. Groselj, D. M. Badine, W. B. Schweizer and A. K. Beck, Helv. Chim. Acta, 2008, 91, 1999; (b) U. Groselj, D. Seebach, D. M. Badine, W. B. Schweizer, A. K. Beck, I. Krossing, P. Klose, Y. Hayashi and T. Uchimaru, Helv. Chim. Acta, 2009, 92, 1225; (c) C. Sparr, W. B. Schweizer, H. M. Senn and R. Gilmour, Angew. Chem., 2009, 121, 3111 (Angew. Chem., Int. Ed., 2009, 48, 3065); (d) U. Groselj, W. B. Schweizer, M.-O. Ebert and D. Seebach, Helv. Chim. Acta, 2009, 92, 1; (e) D. Seebach, U. Groselj, W. B. Schweizer, S. Grimme and C. Mück-Lichtenfeld, Helv. Chim. Acta, 2010, 93, 1; $(f)$ J. B. Brazier, G. Evans, T. J. K. Gibbs, S. J. Coles, M. B. Hursthouse, J. A. Platts and N. C. O. Tomkinson, Org. Lett., 2009, 11, 133; (g) C. Sparr and R. Gilmour, Angew. Chem., 2010, 122, 37 (Angew. Chem., Int. Ed., 2010, 49, 37); (h) I. Fleischer and A. Pfaltz, Chem.-Eur. J., 2010, 16, 1.

3 S. Lakhdar, T. Tokuyasu and H. Mayr, Angew. Chem., 2008, 120, 8851 (Angew. Chem., Int. Ed., 2008, 47, 8723).

4 (a) H. Mayr and M. Patz, Angew. Chem., 1994, 106, 990 (Angew. Chem., Int. Ed. Engl., 1994, 33, 938); (b) H. Mayr, T. Bug, M. F. Gotta, N. Hering, B. Irrgang, B. Janker, B. Kempf, R. Loos, A. R. Ofial, G. Remennikov and H. Schimmel, J. Am. Chem. Soc., 2001, 123, 9500; (c) H. Mayr, B. Kempf and A. R. Ofial, Acc. Chem. Res., 2003, 36, 66; (d) H. Mayr and A. R. Ofial, Pure Appl. Chem., 2005, 77, 1807; (e) H. Mayr and A. R. Ofial, J. Phys. Org. Chem., 2008, 21, 584.

5 For the application of eqn (1) in organocatalysis, see: (a) P. G. Cozzi, F. Benfatti and L. Zoli, Angew. Chem., 2009, 121, 1339 (Angew. Chem., Int. Ed., 2009, 48, 131); (b) F. Benfatti, E. Benedetto and P. G. Cozzi, Chem.-Asian J., 2010, 5, 2047; (c) M. G. Capdevila, F. Benfatti, L. Zoli, M. Stenta and P. G. Cozzi, Chem.-Eur. J., 2010, 16, 11237; (d) A. R. Brown, W.-H. Kuo and E. N. Jacobsen, J. Am. Chem. Soc., 2010, 132, 9286

6 N. A. Paras and D. W. C. MacMillan, J. Am. Chem. Soc., 2001, 123, 4370

7 (a) S. Lakhdar, R. Appel and H. Mayr, Angew. Chem., 2009, 121, 5134 (Angew. Chem., Int. Ed., 2009, 48, 5034); (b) S. Lakhdar, A. R. Ofial and H. Mayr, J. Phys. Org. Chem., 2010, 23, 886 .

8 N. F. Austin, PhD thesis, California Institute of Technology, 2006.

9 A. Albert and E. P. Serjeant, The Determination of Ionization Constants, Chapman and Hall, New York, 3rd edn, 1984.

10 T. A. Nigst, M. Westermaier, A. R. Ofial and H. Mayr, Eur. J. Org. Chem., 2008, 2369.

11 In the case of $\mathbf{2 d}$ and $\mathbf{2 e}$, the intermediate aldehydes $\mathbf{3} \mathbf{d}^{\prime}$ and $3 \mathbf{e}^{\prime}$ were also isolated as described in the ESI $\dagger$.

12 Ref. $2 g$ shows, however, that in methanol solution basic counterions are not needed, because the reaction of $\mathbf{1}-\mathrm{SbF}_{6}$ with $\mathbf{2} \mathbf{f}$ in methanol (rt, $90 \mathrm{~min}$ ) yielded $86 \%$ of $\mathbf{3 f}$ after in situ reduction of the intermediate aldehyde by $\mathrm{NaBH}_{4}$.

13 R. Gordillo, J. Carter and K. N. Houk, Adv. Synth. Catal., 2004 346, 1175. 